\title{
Planning Of Educational Systems Type Sinppe
}

Carlos Miguel Barber Kuri, (E-mail: cbarber@ds.uas.mx), Universidad Anáhuac del Sur, Mexico

\begin{abstract}
Large quantities of educational offers are limited, therefore, opportunities forecasted in an academia - administrative organization have not been responded to according to the demand registered in the few last years. The fact that not everyone agrees on what is to be done has placed a lot of private schools in Mexico and Latin America in a delicate situation, with the latent risk of being closed. The presentation of this case is an example of maturity, heroism and commitment of a group of religious directors and founders of schools in Mexico, the USA and South America, who have been able to face these situations successfully during a critical moment of their institutional life. The problem needs to be addressed in three stages: the administrative, academic and organizational, which have been able to visualize the problem as an interrelated group that is totally dependent. The obtained results are the six year-old product systematized on the part of the whole educational community of this institution as well as their directors, personal founder and the education team who presented the results in the doctoral dissertation concerning this problem.
\end{abstract}

\section{INTRODUCTION}

$\mathscr{I}$

n 1980, the association "Promotion and Human Culture" faced serious problems as a result of a decrease in student registration, the alarming canceling of projects and a lack of organizational administrative structures appropriate for the magnitude of its project. This phenomenon, although not different for many schools in America, became worse as their infrastructure and organization were neglected. For such reasons, it was decided to carry out a series of formal investigations in order to give concrete solutions and to promote strategies of continuous improvement in certain aspects of educational administration. For this idea, the Board decided to hire external experts to obtain their advice in the area of systems planning.

Initially, a team was brought together whose first intervention consisted of identifying the problem, its exemplification and the design of academic administrative batteries for the academic diagnosis of the institution studied.

Results were obtained immediately. The institutional educational panorama pointed out that from 1974 to 1994, 17\% of the schools had been closed. The student population estimated in 1994 was 13,000, 79\% were women and this population had been instructed by 600 non-religious professors and 200 nuns. The academic levels that were offered by the institute were five: kindergarten, elementary, junior high levels 1-3, senior high levels 4-6, and commercial academies.

In January of 1995, the Board undertook the first ratings of studies diagnosed in eight schools located in three different geographical areas; among those that were divided, for convenience. The Mexican Republic. A reflection on the global problem of the institute had already been discussed and analyzed, differentiating causes and effects, dependent and independent variables, outlining the work proposal to be carried out through specific actions.

All tables and charts are available from author. 
The problems identified were:

1. Human resources did not necessarily participate in the educational task. This gave rise to an overload of work for those active nuns and had a direct influence on the academic level of the schools, since the shortage of human elements could diminish the attention to the schools.

2. The lack of vocation, the desertion index and the death rate did not allow for a healthy growth of the institute, and it was feared that in the next 20 years, the number of members would begin to diminish alarmingly if immediate action was not taken.

3. The rapid increase in an advanced average age of the religious population caused the labor force to diminish considerably throughout the years.

4. Application of efforts in divergent actions. Although plans and programs of institutional development existed, the objectives of the institute and lines of action were interpreted in diverse ways, taking attention away from the educational field. This point was treated as one of the main aspects of the research because of its impact and influence on the main problem.

5. The need to increase the religious personnel's academic level who were assigned to the educational field.

6. The inactive participation during the process of formation inside the apostolate fields.

7. The decrease in the national and regional economy that forced students to drop out of these schools and enroll in public schools and which was reflected in a drop student enrollment and income received by schools, an increase in payable documents and a delay in collecting tuition, among others.

8. The resistance to change caused an ignorance of the behavior of the market, the absence of a calculation of tuition and registrations in some schools, the lack of studies supply and demand according to the area, the non- existence of analysis of strengths and weaknesses that identified lines of action according to the specific problem of each school, the lack of updating, the educational personnel's rotation due to a lack of selection tools and recruiting of personnel, the lack of creativity in the design of alternatives for decision making, etc.

The decreasing student registration forecast, based on the behavior of the closing of sections of schools pointed out that, in the event of not orchestrating immediate action, the decrease would occur as an exponential type with an average of $3 \%$ for the following three years, followed by $9 \%$ from the third to the fifth year, ascending to $21 \%$ in the sixth year, and even higher in the following ten years.

\section{METHODOLOGY}

The difficulty and extension of the problem forced the participants to be aware of the fact that insolated results would only partially diminish some of the effects without giving a definitive solution. Initially, the objective assigned to the education team consisted of elevating the student registration of the schools; however, after an advanced investigation, the conclusion showed a need for something more than marketing strategies and optimal management procedures in order to avoid the canceling of the projects. After the first results of the field studies, the need to orchestrate a system of continuous improvement that did not only raise the student registration but rather promoted the development of human resources and gave concrete limits for a functional organization in the schools was identified. The initial hypothesis sustained that the planning process type SINPPE would increase the results of the education administration whenever the theological-philosophical framework was dealt with. 
This supposition was based on a system of continuous improvement in the process of administrative planning, which demanded an order, different follow-up and additional elements; in other words, it required a different focus on internal strategic management, which would be considered as a contribution to the educational administration originated by this study. (Chart 1).

The education team was given the task of revising those concepts adopted by the institution in order to unify contents and to avoid later ambiguities.

The diagnosis tools used by the school were specifically developed to evaluate the plans, objectives, human resources, materials, technical aspects, processes and operations of the educational administration. All the conclusions were reviewed by participating educational communities of each school center. (Chart 2)

The 12 studies were classified according to the directed area, these being: philosophical, managerial, administrative, educational, student, alumni and parents.

The application references were defined in terms of authority, responsibility, handling of information and range of each work group. The number of items processed for each study oscillated between 341 and 355, because not all the interviewed schools had junior-senior high school level or a commercial academy, which made it impossible to survey teachers in these sections.

For the SWOT Analysis, structured questionnaires were designed with a bipolar answer - 'yes or no' - in order to quantify and classify the high-low strengths, weaknesses, opportunities and threats.

The questionnaires were oriented to evaluate the professor's performance, taking into consideration 10 or 14 items, according to the section they belonged to. These studies were answered by the same students in order to evaluate the pedagogic and didactic aspects, professional preparation and personal aspects of their professors.

The transition studies were made up of a series of detailed outlines that included different factors with two different focuses on educational administration. On one side, it was decided to place the traditional focus in Mexico, while on the other side, the pattern of the modern Mexican educational administration. Among these, a scale was distributed from A to E, where the evaluated participant was ranked. (Krazz, Eva 1994: p. 88).

In the batteries, similar questions were included in order to validate the answers of the study. Another indicator that intervened to check the validity of the results was the analysis of each one of the answered items, their relationship with the number of people that gave their answer and the percentage of abstentions for each question. A team member was always present to respond to any doubt on the contents of the batteries.

\section{DEVELOPMENT}

In 1995, a national and institutional educational panorama was finally obtained, pointing out the reality framework; the first analysis of needs was elaborated, the batteries were reviewed and as well, their application references. In 1996, statistical data was drawn up in the schools, however, the casting and statistical analysis for obtaining results to deduce and propose concrete solutions became necessary. That is why it was decided to continue with the design of the computation system that analyzed the information statistically.

In October of the same year, the education team activities project was formally introduced in the 1996-1997 Institutional Programming. This project included the statistical analysis of the first schools interviewed, the presentation of results to the Board which were later presented to the schools, and previously approved by the Council. The presentation of the first results took place in the headquarters, on December 21, 1996. As a result of this meeting, the education team was authorized to continue with the analysis of the other schools. (The results of this work can be seen in Graph 3. 
When concluding the first year of work, the signal objectives were evaluated and captured in the 1997- 1998 Annual Program.

The results of the studies guided the lines of action which were then divided in academic-administrative, philosophical-institutional and administrative - organization. The first of them was carried out with concrete interventions in the schools; based on the results of the diagnostics, for the effect of the presentations, the results were commented on and discussed in a participative way. The agreed solutions were registered in the reports directed to the Board. Other types of interventions were the elaboration of educational projects, the issuing of updated courses and the design of social-economic studies.

The philosophical-institutional line examined in depth the characteristics presented in some religious institutes that have as their mission the human and Christian education, the meaning of ideology, education and their purposes, the moments the ideology had to pass through in order to finally intervene directly on its diffusion and drafting. As a result, the drawing up of this document was made possible along with explicative lines.

The administrative study included the analysis of the historical data of the last 10 years for each school on several indicative matters such as: student registration per academic level, the number of men and women in each group, the number of groups, the breakdown of scholarships and their distribution, registration, tuition and payments, hired personnel, number of religious personnel that are of service in schools and the payroll breakdown, among others. The results were discussed in each school visited in 1998, with a positive answer by the religious personnel and directors. (Graph 4)

In reference to the organizational aspects, the educational project was the task instrument that energized the action, and at the same time included the philosophy that motivated performance. The projects were elaborated on the basis of the ideals of the institute and attended to the special needs of the demographic demarcation where the same community is located.

The educational project coordinated the ideals, purposes, objectives, goals, approaches and functions so that the educational action could be assumed by the community. For their elaboration, the social - economic reality, politics and cultural aspects of the place were studied.

\section{RESULTS}

The conclusions are a product of the measurement and comparison of the results obtained in the schools at four different times.(See chart 5): the first only considered 4 of them, the second concentrated on the results of 8 schools, the third on 12 and the last one on 23 educational centers. Additionally, they registered the progress of the 3 pilot schools in the last 4 years.

The activities orchestrated inside the planning process included:

1. In each of all the schools visited:

- Involving the religious personnel who have an appropriate school level in the educational workload done in the religious communities, to give greater testimony and presence in the schools, to include in the class on Education on Faith, a larger number of nuns who also presented their services in complementary activities to education, which was an encouragement to the educational communities. This indirectly increased the attention at the academic level and the investment dedicated to the development of the religious personnel. This increment was most beneficial to all.

- Presenting the deficiencies observed in the effectiveness of the vocational promotion, the consequences relapsed in the lack of vocation, the devotion lacking on the part of some vocations and the need to obtain concrete results by the vocational promoter. Although the education team only 
had the ability to point out the causes and effects observed on these points, it showed the above in the education encounters so that the corresponding team took the appropriate measures.

- To look for the unification of approaches between the ideology and the institutional mission.

- $\quad$ To propose updated courses for the religious and educational personnel during school recess and vacations.

- $\quad$ To increase registration and tuition, keeping in mind the economic crisis, the niche of an assisted market and the economic area of the place.

- $\quad$ To implant marketing diffusion activities.

- To install Internet communication systems.

- $\quad$ To carry out studies in order to detect market supply.

2. To communicate those other needs detected in the academic-administrative diagnoses that are not the responsibility of the education team.

3. To introduce the "evaluation committee" to the follow up of educational projects. This generated a greater participation and interest in the involved areas. This type of organization began a process of unification of projects at the institutional level.

4. To recommend that the feminine population stay around $60 \%$.

5. To organize topics that propitiate management meetings. This increased communication considerably among the religious personnel who direct and control.

6. To encourage the writing of periodical reports, annuals and work plans. This gave continuity to the actions that were undertaken and diminished the problem of rotation of directors.

7. To use Gantt graphics for the annual programming and unify activities among schools.

8. On the administrative level, the historical analysis of different indicators gave the directors the reality of the institute, allowing them to define concrete and precise objectives.

The results obtained were measured and helped to increase student registration for schools and institutions. The percentage of increase of the student registration of three pilot schools in $98-99$ was $2.4 \%$ on the average, while that of the 30 schools for that same date was $0.5 \%$; the percentage of increase of student registration of the three pilot schools for the 1999-2000 cycle was 3.9\% on the average in relation to a 1.4\% institutional increase in that period. Finally, the number of schools has remained the same from 1995 up to date, and no schools have been closed. 


\section{NOTES}

